ISSN 2073-4344

www.mdpi.com/journal/catalysts

Article

\title{
Titanium-Niobium Oxides as Non-Noble Metal Cathodes for Polymer Electrolyte Fuel Cells
}

\section{Akimitsu Ishihara ${ }^{1, *}$, Yuko Tamura ${ }^{2}$, Mitsuharu Chisaka ${ }^{3}$, Yoshiro Ohgi ${ }^{4}$, Yuji Kohno ${ }^{2}$, Koichi Matsuzawa ${ }^{2}$, Shigenori Mitsushima ${ }^{1,2}$ and Ken-ichiro Ota ${ }^{2}$}

1 Institute of Advanced Sciences, Yokohama National University, 79-5 Tokiwadai, Hodogaya-ku, Yokohama 240-8501, Japan; E-Mail: mitsushi@ynu.ac.jp

2 Green Hydrogen Research Center, Yokohama National University, 79-5 Tokiwadai, Hodogaya-ku, Yokohama 240-8501, Japan; E-Mails: tamura-yuko-zr@ynu.jp (Y.T.); kohnoy@ynu.ac.jp (Y.K.); kmatsu@ynu.ac.jp (K.M.); ken-ota@ynu.ac.jp (K.-i.O.)

3 Department of Electronics and Information Technology, Hirosaki University, 3 Bunkyo-cho, Hirosaki, Aomori 036-8561, Japan; E-Mail: chisaka@eit.hirosaki-u.ac.jp

4 Kumamoto Industrial Research Institute, 3-11-38 Azuma-cho, Azuma-ku, Kumamoto, Kumamoto 862-0901, Japan; E-Mail: ohgi@kumamoto-iri.jp

* Author to whom correspondence should be addressed; E-Mail: a-ishi@ynu.ac.jp; Tel.: +81-45-339-4021; Fax: +81-45-339-4024.

Academic Editor: Minhua Shao

Received: 2 June 2015 / Accepted: 14 July 2015 / Published: 17 July 2015

\begin{abstract}
In order to develop noble-metal- and carbon-free cathodes, titanium-niobium oxides were prepared as active materials for oxide-based cathodes and the factors affecting the oxygen reduction reaction (ORR) activity were evaluated. The high concentration sol-gel method was employed to prepare the precursor. Heat treatment in Ar containing 4\% $\mathrm{H}_{2}$ at $700-900{ }^{\circ} \mathrm{C}$ was effective for conferring ORR activity to the oxide. Notably, the onset potential for the ORR of the catalyst prepared at $700{ }^{\circ} \mathrm{C}$ was approximately $1.0 \mathrm{~V}$ $v s$. RHE, resulting in high quality active sites for the ORR. X-ray (diffraction and photoelectron spectroscopic) analyses and ionization potential measurements suggested that localized electronic energy levels were produced via heat treatment under reductive atmosphere. Adsorption of oxygen molecules on the oxide may be governed by the localized electronic energy levels produced by the valence changes induced by substitutional metal ions and/or oxygen vacancies.
\end{abstract}


Keywords: titanium-niobium oxides; oxygen reduction reaction; polymer electrolyte fuel cells; non-platinum cathode

\section{Introduction}

Polymer electrolyte fuel cells (PEFCs) offer many advantages, including high power density, high energy conversion efficiency, and lower operating temperatures. PEFCs are therefore suitable as power sources for vehicles and residential co-generation power systems. However, the use of Pt as a cathode electrocatalyst for PEFCs is problematic due to the high cost and limited availability of Pt, and insufficient stability of these catalysts. To successfully commercialize PEFCs, low-cost non-platinum cathode catalysts with high stability must be developed.

Since Jasinski discovered the oxygen reduction reaction (ORR) activity of cobalt phthalocyanine [1], the search for promising non-platinum ORR catalysts has led to the development of several cobalt- and iron-containing catalysts [2,3]. Approaches to enhance the activity of these catalysts include the use and optimization of carbon supports and heat treatment conditions. Heat treatment of iron salts adsorbed on carbon supports under ammonia gas is a recent breakthrough that produces catalysts with high ORR activities comparable to that of platinum-based catalysts [4]. Despite significant improvement of the ORR activity of non-platinum catalysts, issues regarding their long-term durability remain unresolved.

Based on the high stability of Group 4 and 5 metal oxide-based compounds in acidic media, low cost, $[5,6]$ and lower solubility in acid solution compared to platinum-based catalysts, these compounds have piqued our interest as they are expected to be stable even under the conditions encountered at the PEFC cathode. Recently, we successfully synthesized oxide-based nanoparticles using oxy-metal phthalocyanines $(\mathrm{MeOPc} ; \mathrm{Me}=\mathrm{Ta}, \mathrm{Zr}$, and $\mathrm{Ti}$ ) as the starting material and multi-walled carbon nanotubes (MWCNTs) as the support as well as the electro-conductive material [7,8]. However, carbon materials are easily oxidized at high potentials with a consequent decrease of the ORR activity due to degradation of the electron conduction paths [8]. Thus, carbon-free electrocatalysts are required to achieve high durability of the oxide-based cathodes. To prepare noble-metal- and carbon-free cathodes, the basic approach is to combine electro-conductive oxides with oxides that possess ORR active sites.

Previously, we prepared noble-metal- and carbon-free cathodes comprising niobium-titanium oxides with active sites and titanium oxides with magneli phase $\mathrm{Ti}_{4} \mathrm{O}_{7}$ as the electro-conductive material (i.e., $\mathrm{Ti}_{x} \mathrm{Nb}_{y} \mathrm{O}_{z}+\mathrm{Ti}_{4} \mathrm{O}_{7}$ ) [9]. The highest onset potential of $\mathrm{Ti}_{x} \mathrm{Nb}_{y} \mathrm{O}_{z}+\mathrm{Ti}_{4} \mathrm{O}_{7}$ was $c a .1 .1 \mathrm{~V}$ versus the reversible hydrogen electrode (RHE). No degradation of the ORR performance of $\mathrm{Ti}_{x} \mathrm{Nb}_{y} \mathrm{O}_{z}+\mathrm{Ti}_{4} \mathrm{O}_{7}$ was observed during the start-stop and load cycle tests in $0.1 \mathrm{~mol} \cdot \mathrm{dm}^{-3} \mathrm{H}_{2} \mathrm{SO}_{4}$ at $80{ }^{\circ} \mathrm{C}$, where these conditions are close to the operating conditions of the existing PEFC [10]. Therefore, we successfully demonstrated superior durability of noble-metal- and carbon-free oxide-based cathodes under the cathode conditions of the PEFC.

However, the ORR activities of the $\mathrm{Ti}_{x} \mathrm{Nb}_{y} \mathrm{O}_{z}+\mathrm{Ti}_{4} \mathrm{O}_{7}$ catalysts were still low because these catalysts were prepared under argon containing $4 \%$ hydrogen at high temperature, $1050{ }^{\circ} \mathrm{C}$, where $\mathrm{Ti}_{4} \mathrm{O}_{7}$ was 
generated by the reduction of $\mathrm{TiO}_{2}$. That is, the preparation conditions encouraged the formation of $\mathrm{Ti}_{4} \mathrm{O}_{7}$ but were not optimal for the formation of niobium-titanium oxides with active sites. Domen et al. demonstrated that $\mathrm{Nb}$-doped $\mathrm{TiO}_{2}$ synthesized by the oxidation of $\mathrm{Nb}$-doped $\mathrm{TiN}$ nanoparticles exhibited definite ORR activity and high long-term stability in acidic solutions [11]. However, these catalysts contained carbon residues that functioned to improve the conductivity between the particle aggregates. The preparation conditions used in that study were thus not suitable for the formation of ORR active titanium-niobium oxides without carbon. Consequently, it is necessary to separately optimize the conditions for the formation of titanium-niobium oxides with active sites and the formation of electro-conductive oxides. In this study, we focus on the formation of active sites on titanium-niobium oxides using a high concentration sol-gel method. The factors that influence the ORR activity in the absence of a carbon support are evaluated. However, it is necessary to obtain sufficient electro-conductivity to evaluate the ORR activity of the titanium-niobium oxides. Even a glassy carbon (GC) rod is heat-treated in air, an insulating oxide film is not formed on the surface. Therefore, the GC rod is superior to use as a substrate for the working electrode. The present strategy utilizes pre-heat-treatment $\left(600{ }^{\circ} \mathrm{C}\right.$ in air for $\left.10 \mathrm{~min}\right)$ to achieve sufficient electrical contact between the titanium-niobium oxides and the GC substrate. It is necessary to secure the sufficient electro-conductivity between oxide-based catalysts and conductive oxide support when carbon-free cathodes are prepared. For example, the electro-conductive oxide network is made preparations in advance. Then, after oxide-based precursor is supported on the network it is heat-treated to create the ORR active sites and to obtain sufficient electro-conductivity. In this study, the effects of the preparation conditions, such as the gas atmosphere and heat treatment temperatures, on the ORR activity of the titanium-niobium oxides employing a GC rod are evaluated.

\section{Results and Discussion}

\subsection{Characterization of Catalysts}

We prepared the titanium-niobium oxide samples with the charged total composition of $\mathrm{Ti}_{0.841} \mathrm{Nb}_{0.126} \mathrm{O}_{2}$. Figure 1 shows the X-ray diffraction (XRD) patterns of the titanium-niobium oxide samples prepared at $600,700,800,900$, and $1050{ }^{\circ} \mathrm{C}$ (a) in air and (b) in Ar containing $4 \% \mathrm{H}_{2}$. The crystalline phase of the catalysts prepared by heat treatment in air at temperatures between 600 and $900{ }^{\circ} \mathrm{C}$ was identified as anatase $\mathrm{TiO}_{2}$ (JCPDS no. 00-021-1272), indicating that the niobium atoms were incorporated into the $\mathrm{TiO}_{2}$ anatase structure. According to phase diagram of $\mathrm{TiO}_{2}-\mathrm{Nb}_{2} \mathrm{O}_{5}$ [12], $\mathrm{Nb}(\mathrm{V})$ ions dissolve into $\mathrm{TiO}_{2}$ rutile structure only below $c a .10$ atomic \% in this temperature range. On the other hand, quasi-stable phase, $\mathrm{TiO}_{2}$ anatase structure, can dissolve more $\mathrm{Nb}(\mathrm{V})$ ions. The phase transition from anatase to rutile occurred at temperatures above $900{ }^{\circ} \mathrm{C}$. For samples prepared at higher temperatures, peaks corresponding to the rutile $\mathrm{TiO}_{2}$ (JCPDS no. 00-021-1276) and $\mathrm{TiNb}_{2} \mathrm{O}_{7}$ (JCPDS no. 1001270) phases were observed. This is because the $\mathrm{Nb}(\mathrm{V})$ ions that cannot dissolve in the $\mathrm{TiO}_{2}$ rutile structure forms complex oxides $\mathrm{TiNb}_{2} \mathrm{O}_{7}$ that is solid solution of $\mathrm{TiO}_{2}$ and $\mathrm{Nb}_{2} \mathrm{O}_{5}$. Simultaneously, $\mathrm{Nb}$-containing phases such as $\mathrm{TiNb}_{2} \mathrm{O}_{7}$ appeared at $1050{ }^{\circ} \mathrm{C}$. These results are consistent with previous observations [13]. 

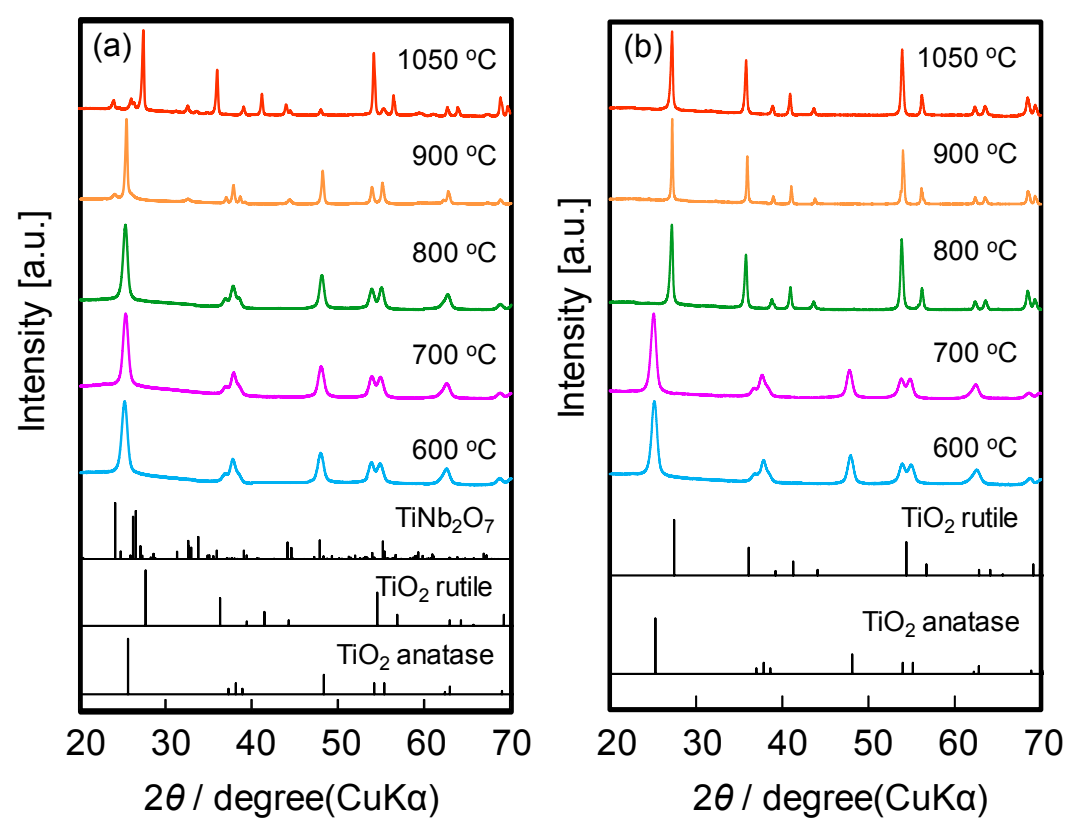

Figure 1. XRD patterns of titanium-niobium oxides prepared at 600, 700, 800, 900, and $1050{ }^{\circ} \mathrm{C}$ (a) in air and (b) in Ar containing 4\% $\mathrm{H}_{2}$.

The crystalline phase of the samples subjected to heat treatment at 600 and $700{ }^{\circ} \mathrm{C}$ in $\mathrm{Ar}$ containing $4 \% \mathrm{H}_{2}$ could be indexed to the $\mathrm{TiO}_{2}$ anatase structure. However, the samples prepared at temperatures above $800{ }^{\circ} \mathrm{C}$ under this reductive atmosphere could be indexed to rutile $\mathrm{TiO}_{2}$ with no $\mathrm{Nb}_{2} \mathrm{O}_{5}$ peaks. The shift of the XRD peaks to lower angles (Figure S1) with increasing treatment temperature suggested that the catalysts are substitutional solid solutions in which the niobium ions substitute titanium ions in the rutile $\mathrm{TiO}_{2}$ lattice. Compared to formation of the rutile phase above $900{ }^{\circ} \mathrm{C}$ for the samples heat-treated in air, the rutile was phase formed at $800{ }^{\circ} \mathrm{C}$ under reductive atmosphere. Thus, the transformation from the anatase to rutile phase occurred at lower temperature under reductive atmosphere. In addition, the substitutional solid solution (rutile phase) was stable up to $1050{ }^{\circ} \mathrm{C}$ under reductive atmosphere. The XRD analysis clearly demonstrated that the $\mathrm{TiO}_{2}$ rutile-based structure was more stable under reductive atmosphere than in air. This stabilization of the $\mathrm{TiO}_{2}$ rutile-based structure is not predicted from the viewpoint of thermochemistry. The role of heat-treatment under reductive atmosphere and doped niobium ions must be elucidated.

Figures 2 and S2 show scanning electron microscopy (SEM) images of the titanium-niobium oxides prepared at $600{ }^{\circ} \mathrm{C}$ in air, and $600,700,800,900$, and $1050{ }^{\circ} \mathrm{C}$ in Ar containing $4 \% \mathrm{H}_{2}$. The SEM images demonstrate that the surface morphology of the titanium-niobium oxides depends on the heat treatment temperature. Very little difference in the surface morphology was observed for the samples prepared by heat treatment at $600{ }^{\circ} \mathrm{C}$ under different atmospheres. The particle size of the catalysts prepared at $600{ }^{\circ} \mathrm{C}$ was $c a$. several tens of nanometers. A significant change in the morphologies of the catalysts was observed with treatment at $800{ }^{\circ} \mathrm{C}$, indicative of particle aggregation above $800{ }^{\circ} \mathrm{C}$. Aggregation became progressive with increasing heat treatment temperatures. Thus, the surface area of the catalysts decreased with temperature, especially above $800^{\circ} \mathrm{C}$. 


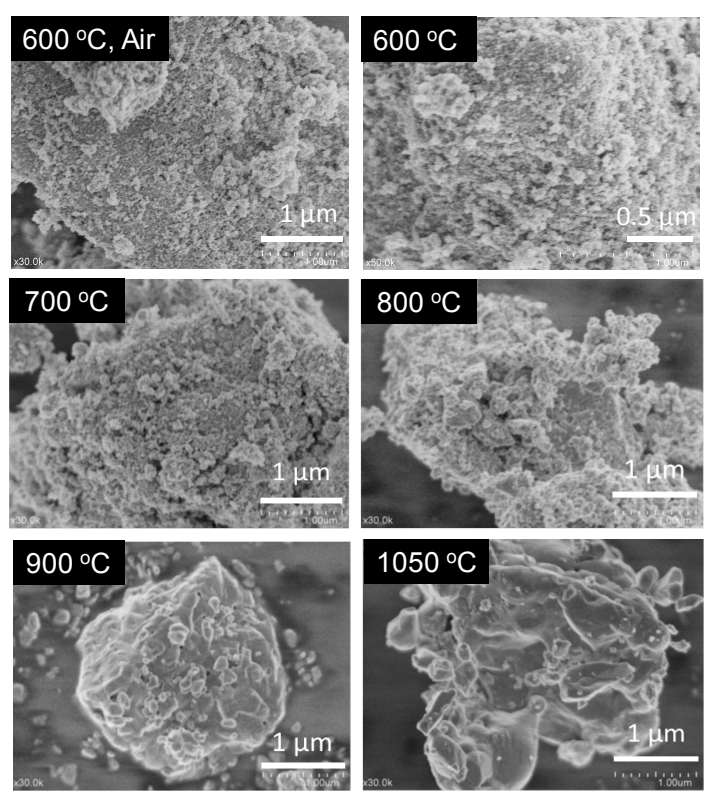

Figure 2. SEM images of the titanium-niobium oxides prepared at $600{ }^{\circ} \mathrm{C}$ in air, and 600 , 700, 800, 900, and $1050{ }^{\circ} \mathrm{C}$ in Ar containing 4\% $\mathrm{H}_{2}$.

Figure 3 shows photographs of the catalysts prepared at $600{ }^{\circ} \mathrm{C}$ in air, and $600,700,800,900$, and $1050{ }^{\circ} \mathrm{C}$ in Ar containing $4 \% \mathrm{H}_{2}$. The powder heat-treated at $600{ }^{\circ} \mathrm{C}$ was white, as expected from the wide bandgap of $\mathrm{TiO}_{2}$ (all samples treated in air were white). On the other hand, the samples heat-treated at $600{ }^{\circ} \mathrm{C}$ under reductive atmosphere had a light-blue color and the color deepened with increasing temperature. This color change suggests that there is some difference in the electronic energy levels of the samples prepared under reductive atmosphere relative to those prepared in air. Namely, the difference between the highest occupied and lowest unoccupied electronic energy levels decreases with increasing temperature. This color change suggests the development of a localized energy level of electrons in the bandgap of $\mathrm{TiO}_{2}$.

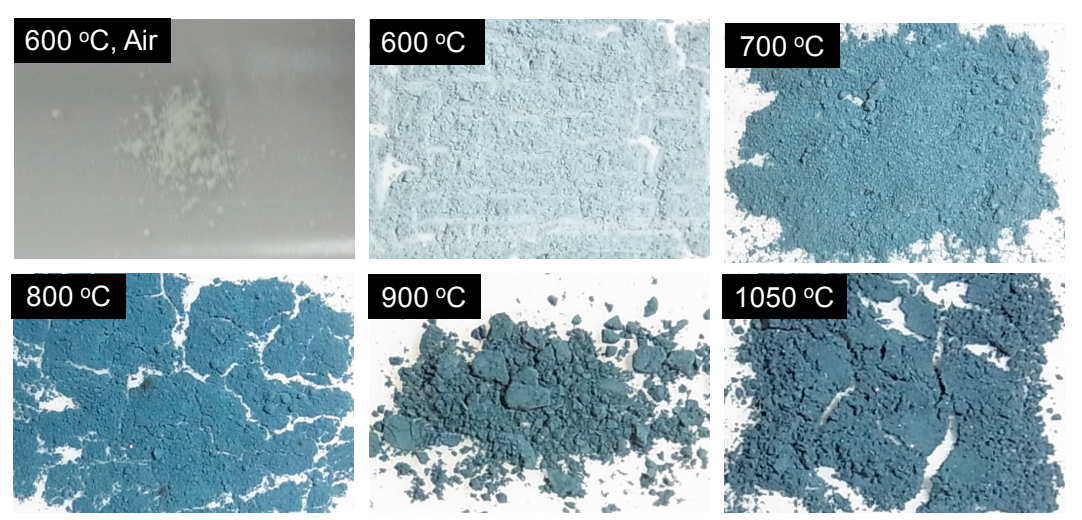

Figure 3. Photographs of the catalysts prepared at $600{ }^{\circ} \mathrm{C}$ in air, and $600,700,800,900$, and $1050{ }^{\circ} \mathrm{C}$ in Ar containing $4 \% \mathrm{H}_{2}$.

Figure 4a shows the Ti $2 p$ XPS spectra of the catalysts prepared at $800{ }^{\circ} \mathrm{C}$ in air and in $\mathrm{Ar}$ containing 4\% $\mathrm{H}_{2}$. As anticipated, the Ti $2 \mathrm{p}$ XPS spectra revealed that Ti adopted the tetravalent state for the specimen heat-treated in air based on the $2 \mathrm{p}_{3 / 2}$ peak $\left(\mathrm{TiO}_{2} ; 458.8 \mathrm{eV}\right.$ [14]). On the other hand, a low 
valence state, i.e., $\mathrm{Ti}^{3+}\left(\mathrm{Ti}_{2} \mathrm{O}_{3} ; 456.8 \mathrm{eV}\right.$ [15]), was observed for the catalyst heat-treated at $800{ }^{\circ} \mathrm{C}$ under reductive atmosphere. The ratios of $\mathrm{Ti}^{3+} / \mathrm{Ti}^{4+}$ calculated from areas of the XPS spectra of the specimens heat-treated at $800{ }^{\circ} \mathrm{C}$ in air and in $\mathrm{Ar}$ containing $4 \% \mathrm{H}_{2}$ were $5.0 \%$ and $10 \%$, respectively. The ratio of the specimen prepared under reductive atmosphere was twice as large as that prepared in air. In addition, the total atomic ratio of $\mathrm{Nb} / \mathrm{Ti}$ is 0.15 according to the charged total composition of $\mathrm{Ti}_{0.841} \mathrm{Nb}_{0.126} \mathrm{O}_{2}$. The atomic ratios of $\mathrm{Nb} / \mathrm{Ti}$ calculated from areas of the XPS spectra of the specimens heat-treated at $800{ }^{\circ} \mathrm{C}$ in air and in $\mathrm{Ar}$ containing $4 \% \mathrm{H}_{2}$ were 0.43 and 0.23 , respectively. Both ratios are larger than the total atomic ratio, suggested that the niobium ions accumulate the surface of the oxide particles. In particular, the $\mathrm{Nb} / \mathrm{Ti}$ ratio of the specimen heat-treated in air was about three times larger than the total atomic ratio. As mentioned in XRD patterns, because the rutile $\mathrm{TiO}_{2}$ phase cannot dissolve the $\mathrm{Nb}(\mathrm{V})$ ions, the dissolved $\mathrm{Nb}(\mathrm{V})$ ions in the anatase $\mathrm{TiO}_{2}$ phase began to accumulate near the surface of the particles at higher temperature heat treatment.

Figure $4 \mathrm{~b}$ shows the Ti $2 \mathrm{p}$ XPS spectra of the catalysts prepared at $600,700,800,900$, and $1050{ }^{\circ} \mathrm{C}$ in Ar containing $4 \% \mathrm{H}_{2}$. Low valence states of Ti were observed for the catalyst heat-treated at $600{ }^{\circ} \mathrm{C}$ under reductive atmosphere, suggesting that the oxides underwent little reduction at $600{ }^{\circ} \mathrm{C}$ in $\mathrm{Ar}$ containing $4 \% \mathrm{H}_{2}$ upon treatment for $10 \mathrm{~min}$. Heat-treatment above $700{ }^{\circ} \mathrm{C}$ under reductive atmosphere resulted in the formation of low valence state Ti as shown in Figure 4.
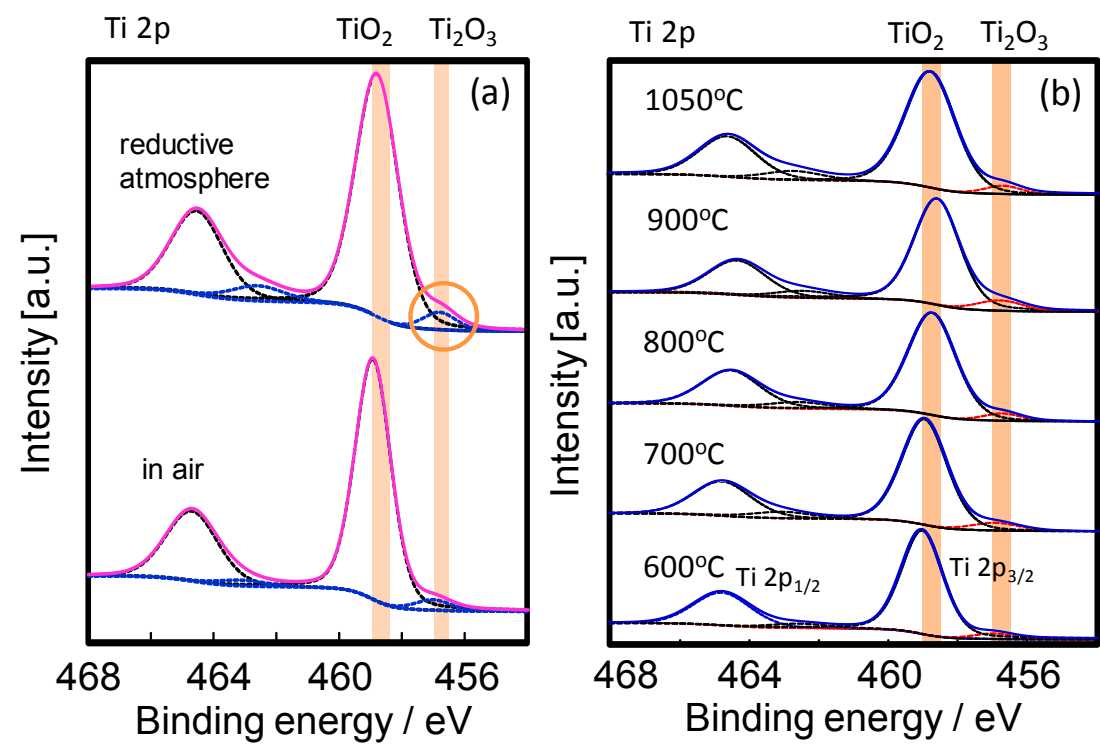

Figure 4. Ti $2 \mathrm{p}$ XPS spectra of the catalysts prepared at $800{ }^{\circ} \mathrm{C}$ in air and in Ar containing $4 \% \mathrm{H}_{2}$ (a) and prepared at 600, 700, 800, 900, and $1050{ }^{\circ} \mathrm{C}$ in Ar containing $4 \% \mathrm{H}_{2}$ (b).

Figure 5a shows the dependence of the ratios of $\mathrm{Ti}^{3+} / \mathrm{Ti}^{4+}$ (expressed as $S_{\mathrm{Ti}(\mathrm{III})} / S_{\mathrm{Ti}(\mathrm{IV})}$ ) calculated from areas of the XPS spectra of the specimens heat-treated under reductive atmosphere on the temperature. The ratio of $\mathrm{Ti}^{3+} / \mathrm{Ti}^{4+}$ of the specimen prepared at $600{ }^{\circ} \mathrm{C}$ is $6.7 \%$. $\mathrm{Ti}^{3+}$ ions are produced by the substitution of the $\mathrm{Nb}^{5+}$ ions with $\mathrm{Ti}^{4+}$ ions of the $\mathrm{TiO}_{2}$ lattice. Figure $5 \mathrm{~b}$ shows the $\mathrm{Nb}$ $3 \mathrm{~d}$ XPS spectra of the catalysts prepared at $600,700,800,900$, and $1050{ }^{\circ} \mathrm{C}$ in $\mathrm{Ar}$ containing $4 \% \mathrm{H}_{2}$. The peak in the $\mathrm{Nb} 3 \mathrm{~d}$ spectra shifted to higher binding energy $\left(\mathrm{NbO}_{2} ; 205.3 \mathrm{eV}[16], \mathrm{Nb}_{2} \mathrm{O}_{5}\right.$; $207.1 \mathrm{eV}$ [17]) with increasing heat treatment temperatures, in contrast with the Ti $2 \mathrm{p}$ peak. Therefore, 
the $\mathrm{Nb} 3 \mathrm{~d}$ XPS spectra revealed that most of $\mathrm{Nb}$ ions were highest oxidation state, $5+$. Thus, the state of the specimens can be expressed as $\mathrm{Ti}(\mathrm{IV})_{1-2 x} \mathrm{Ti}(\mathrm{III})_{x} \mathrm{Nb}(\mathrm{V})_{x} \mathrm{O}_{2}$. If all $\mathrm{Nb}$ ions substitute $\mathrm{Ti}^{4+}$ ions of the $\mathrm{TiO}_{2}$ lattice as $\mathrm{Nb}(\mathrm{V})$ ions, the composition is $\mathrm{Ti}(\mathrm{IV})_{0.74} \mathrm{Ti}(\mathrm{III})_{0.13} \mathrm{Nb}(\mathrm{V})_{0.13} \mathrm{O}_{2}$. Therefore, in that case, the ratio of $\mathrm{Ti}^{3+} / \mathrm{Ti}^{4+}$ is calculated to be $c a$. $18 \%$. The ratio of $\mathrm{Ti}^{3+} / \mathrm{Ti}^{4+}$ at $600{ }^{\circ} \mathrm{C}, c a$. $6.7 \%$, was smaller than $18 \%$, indicating that the $\mathrm{Nb}(\mathrm{V})$ ions did not sufficiently incorporate into the $\mathrm{TiO}_{2}$ lattice at $600{ }^{\circ} \mathrm{C}$. As shown in Figure $5 \mathrm{a}$, the ratio of $\mathrm{Ti}^{3+} / \mathrm{Ti}^{4+}$ increased with increasing temperature from $600{ }^{\circ} \mathrm{C}$ to $700{ }^{\circ} \mathrm{C}$ and saturated around $10 \%$. These results deduced that reductive heat-treatment above $700{ }^{\circ} \mathrm{C}$ induced the formation of low valence state $\mathrm{Ti}$.
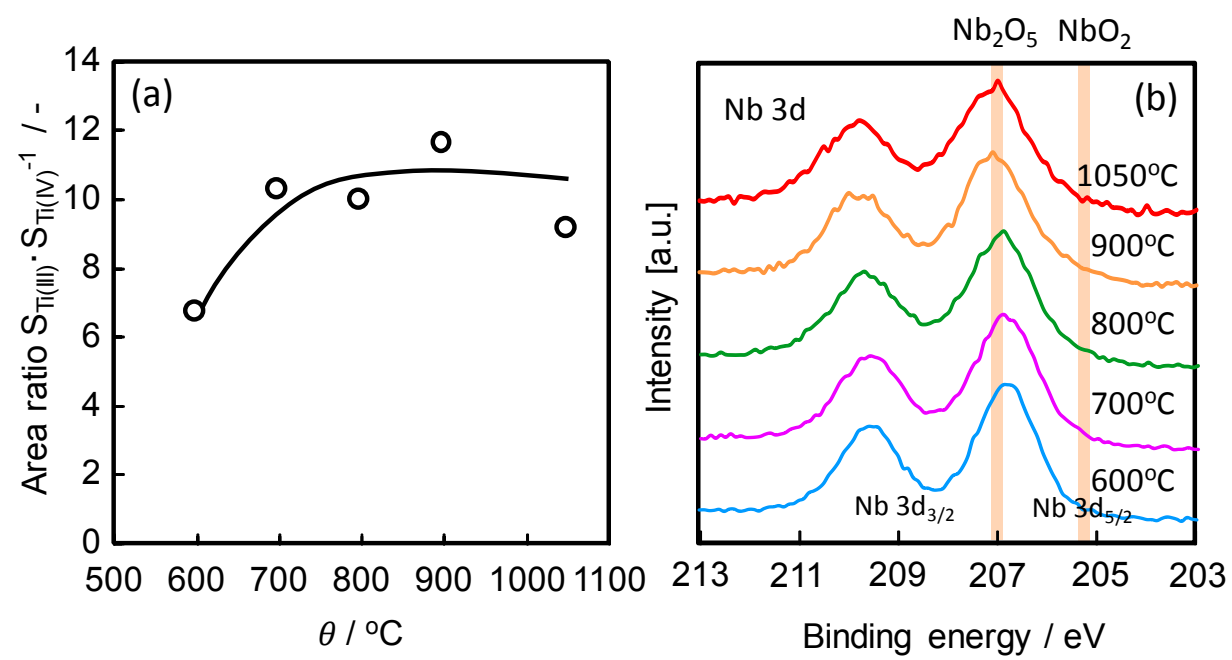

Figure 5. (a) Dependence of the ratios of $\mathrm{Ti}^{3+} / \mathrm{Ti}^{4+}, S_{\mathrm{Ti}(\mathrm{III})} / S_{\mathrm{Ti}(\mathrm{IV}) \text {, calculated from areas of }}$ the XPS spectra of the specimens heat-treated under reductive atmosphere on the temperature. (b) $\mathrm{Nb} 3 \mathrm{~d}$ XPS spectra of the catalysts prepared at $600,700,800,900$, and $1050{ }^{\circ} \mathrm{C}$ in $\mathrm{Ar}$ containing $4 \% \mathrm{H}_{2}$.

Figure 6 shows the dependence of the atomic ratio of $\mathrm{Nb} / \mathrm{Ti}$ calculated from XPS spectra of the specimens prepared under reductive atmosphere on the heat treatment temperature. The atomic ratio of $\mathrm{Nb} / \mathrm{Ti}$ decreased with increasing temperature above $700{ }^{\circ} \mathrm{C}$ and approached the bulk value at $1050{ }^{\circ} \mathrm{C}$. The XRD patterns revealed that the bulk phase transition occurred between 700 and $800{ }^{\circ} \mathrm{C}$ under reductive atmosphere. The XPS spectra indicated that the titanium ions near the surface were reduced and the $\mathrm{Nb}(\mathrm{V})$ ions near the surface incorporated into the $\mathrm{TiO}_{2}$ lattice at $c a .700{ }^{\circ} \mathrm{C}$. Therefore, the phase transition was probably caused by a change in the valence of titanium. We previously demonstrated that tantalum and zirconium oxide-based catalysts had some oxygen vacancies that acted as active sites for the ORR [6]. In case of the titanium-niobium oxide system, the low valence state of the metal ions does not always indicate the presence of oxygen vacancies. The low valence state of the metal ions can be achieved even in the absence of oxygen vacancies because the highest valence states of titanium and niobium are different. The relationship between the presence of oxygen vacancies and the active sites remains a topic for further study. 


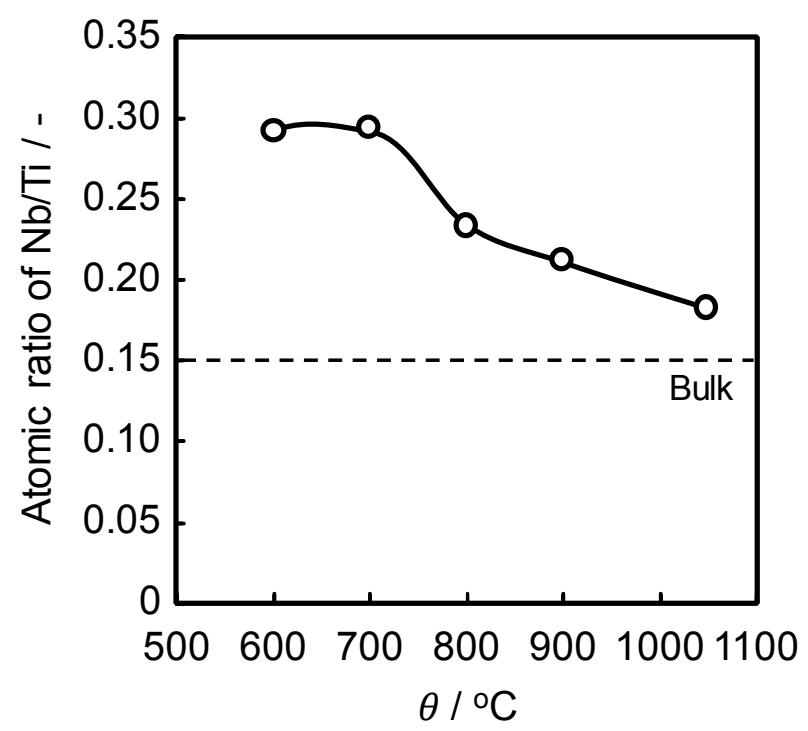

Figure 6. Dependence of the atomic ratio of $\mathrm{Nb} / \mathrm{Ti}$ calculated from XPS spectra of the specimens prepared under reductive atmosphere on the heat treatment temperature.

It was difficult to evaluate the differences in the electronic state of the catalysts heat-treated under reductive atmosphere at temperatures between 700 and $1050{ }^{\circ} \mathrm{C}$ based on the XPS spectra, as shown in Figures $4 \mathrm{~b}$ and $5 \mathrm{a}$. Thus, the ionization potential of the specimens was used as a parameter to evaluate these differences. The ionization potentials of the specimens were measured using a photoelectron spectrometer surface analyzer in order to investigate the differences in the surfaces of the specimens heat-treated in reductive atmosphere at different temperatures. Figure $7 \mathrm{a}$ shows the relationship between the square root of the photoelectric quantum yield and the photon energy (that is, the photoelectron spectra of the specimens heat-treated at $800{ }^{\circ} \mathrm{C}$ in air or in Ar containing $4 \% \mathrm{H}_{2}$ ). The square root of the photoelectric quantum yield increased linearly with an increase in the photon energy applied to each specimen. The slope of the straight line reflects the tendency of the photoelectron emission of the specimens, that is, the density of state of the electrons near the Fermi level. Fewer photoelectrons were emitted in the case of the catalyst prepared in air. The slope of the straight line for the specimen heat-treated in air, where $\mathrm{TiO}_{2}$ was identified on the sample surface by XPS, was apparently lower than that of the congener prepared under reductive atmosphere. It is remarkable that the slope of this plot was steeper for the specimen prepared in Ar containing 4\% $\mathrm{H}_{2}$. The intersection between the straight line and the background line in the photoelectron spectra provides the threshold energy corresponding to the photoelectric ionization potential. The photoelectric ionization potential corresponds to the highest energy level of the electrons in the materials. The ionization potential is directly affected by the localized electronic levels of the lattice defects and impurities in the metal oxides, such as valence changes due to substitutional metal ions, oxygen vacancies, and donor impurities. 
Figure $7 \mathrm{~b}$ shows the dependence of the ionization potential of the catalysts prepared at 600,800 , and $1050{ }^{\circ} \mathrm{C}$ in air, and $600,700,800,900$, and $1050{ }^{\circ} \mathrm{C}$ in Ar containing $4 \% \mathrm{H}_{2}$ on the heat treatment temperature, $\theta$. The ionization potential of commercial rutile and anatase $\mathrm{TiO}_{2}$ is $5.8 \mathrm{eV}$. The ionization potential was the same (i.e., ca. $5.8 \mathrm{eV}$ ) for the catalysts prepared at 600 , 800, and $1050{ }^{\circ} \mathrm{C}$ in air, suggesting that the surface of the catalysts prepared in air had few localized electronic levels from lattice defects and impurities in the metal oxides, similar to commercial $\mathrm{TiO}_{2}$. On the other hand, the ionization potentials of the catalysts prepared under reductive atmosphere decreased with increasing temperature. The decrease in the ionization potential reflects an increase in the localized electronic levels. In other words, the valence changes due to substitutional metal ions, oxygen vacancies, and donor impurities increase with increasing temperature.
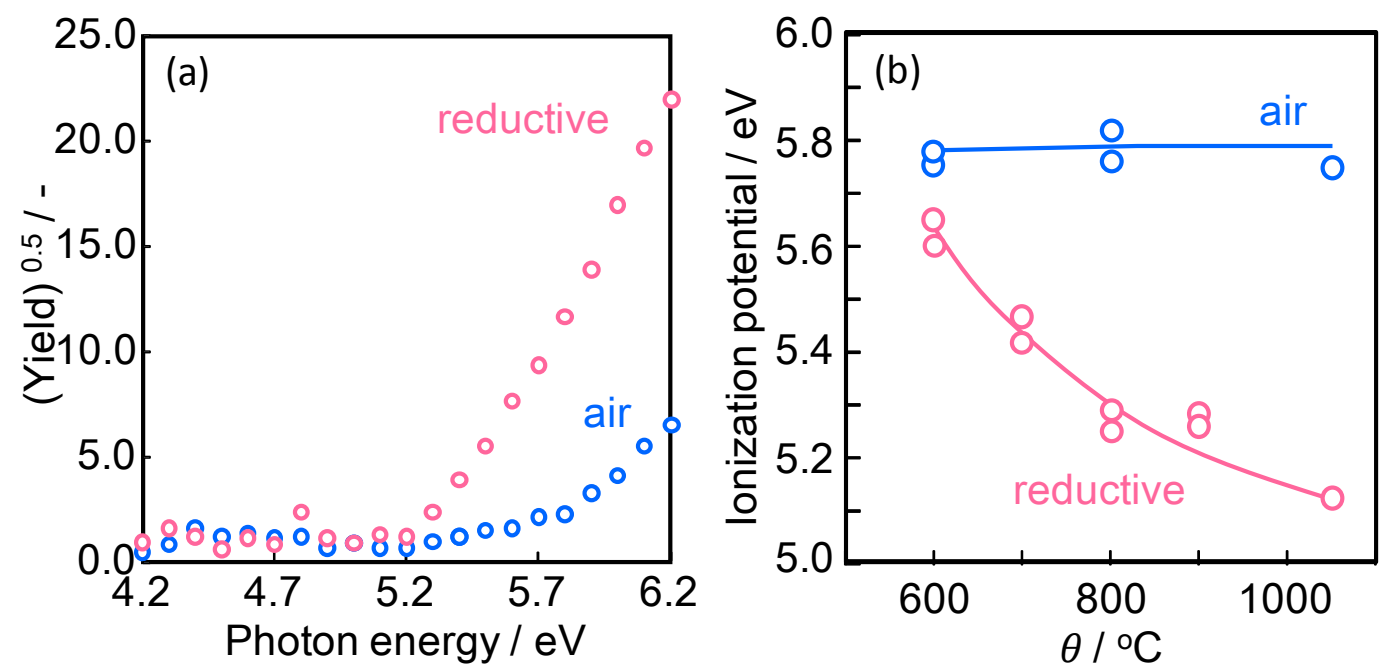

Figure 7. (a) Relationship between the square root of the photoelectric quantum yield $\left(Y^{1 / 2}\right)$ and the photon energy of the specimens heat-treated at $800{ }^{\circ} \mathrm{C}$ in air or in $\mathrm{Ar}$ containing $4 \% \mathrm{H}_{2}$. (b) Dependence of the ionization potential of the catalysts prepared at 600,800 , and $1050{ }^{\circ} \mathrm{C}$ in air, and $600,700,800,900$, and $1050{ }^{\circ} \mathrm{C}$ in Ar containing $4 \% \mathrm{H}_{2}$ on the heat treatment temperature, $\theta$.

\subsection{Oxygen Reduction Activity in Acidic Media}

Figure $8 \mathrm{a}$ shows the potential-ioRR curves for the catalysts prepared at 600,700 , and $1050{ }^{\circ} \mathrm{C}$ in $\mathrm{Ar}$ containing $4 \% \mathrm{H}_{2}$. The heat treatment temperature apparently affected the ORR activity. We focused on the ORR activity in the higher potential region. Figure $8 \mathrm{~b}$ shows the potential-ionR curves for the catalysts prepared at $600,700,800,900$, and $1050{ }^{\circ} \mathrm{C}$ in Ar containing $4 \% \mathrm{H}_{2}$. All samples prepared in air had a low ORR current in the potential range above $0.6 \mathrm{~V}$, indicating that these catalysts have low ORR activity. On the other hand, although the ORR current was low, the catalysts prepared under reductive atmosphere exhibited some ORR activity. In particular, the onset potential of the ORR for the catalyst prepared at $700{ }^{\circ} \mathrm{C}$ was approximately $1.0 \mathrm{~V} v s$. RHE. This high onset potential indicates the good suitability of the active sites for the ORR. Therefore, high quality active sites were created by heat treatment at $700{ }^{\circ} \mathrm{C}$ under reductive atmosphere. 

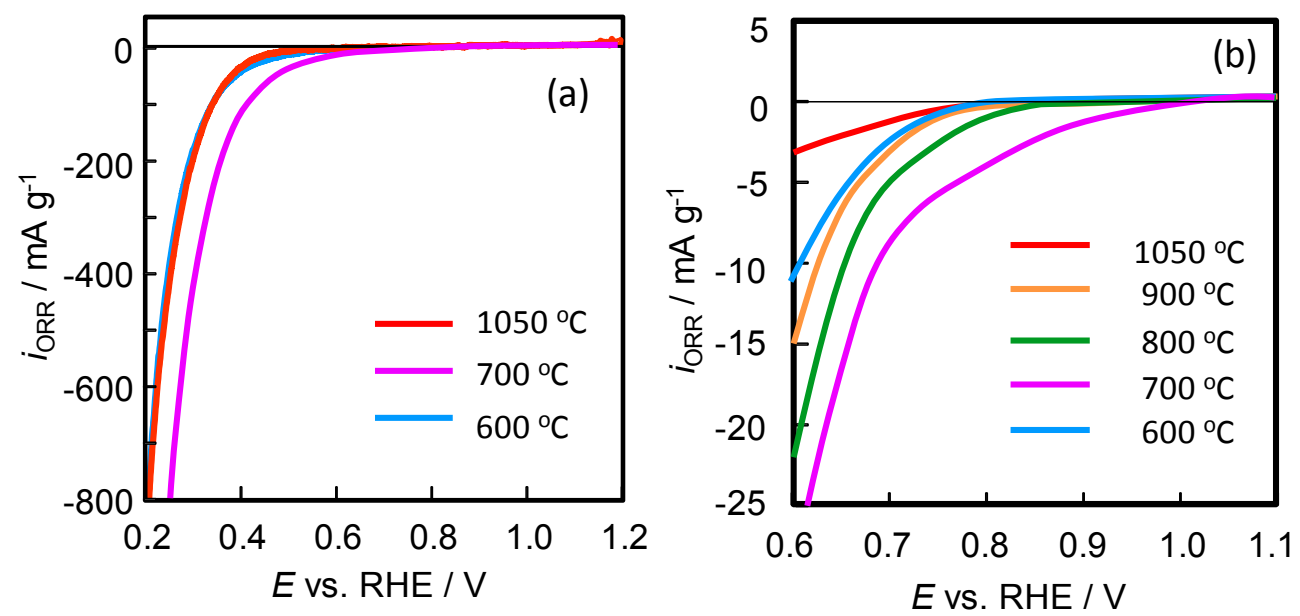

Figure 8. (a) Potential-iorR curves for the catalysts prepared 600,700 , and $1050{ }^{\circ} \mathrm{C}$ in $\mathrm{Ar}$ containing $4 \% \mathrm{H}_{2}$ and (b) potential-ioRR curves in the higher potential region for the catalysts prepared $600,700,800,900$, and $1050{ }^{\circ} \mathrm{C}$ in $\mathrm{Ar}$ containing $4 \% \mathrm{H}_{2}$.

Figure 9 shows the dependence of the iORR@0.7 V on the heat-treatment temperature for the samples prepared under reductive atmosphere. The i ORR@0.7 V reached a maximum around $700{ }^{\circ} \mathrm{C}$. The $i$ ORR presented in Figure 9 is based on the mass of the catalysts loaded on the GC rod. As shown in Figures 2 and S2, the surface area of the catalysts declined precipitously above $800{ }^{\circ} \mathrm{C}$. Thus, the decrease in the iORR @ $0.7 \mathrm{~V}$ above $800{ }^{\circ} \mathrm{C}$ seems to be due to the decrease in the surface area. To evaluate the specific activity (i.e., the ORR current density based on surface area) the actual surface area of the oxides must be estimated. However, it is difficult to estimate the surface area of the oxides because neither hydrogen nor $\mathrm{CO}$ is adsorbed by the oxides. Therefore, the electrical charges of the double layer of the catalysts calculated from the cyclic voltammogram (CV) in $\mathrm{N}_{2}$ atmosphere were used to evaluate the apparent specific activity of the catalysts. Figure S3 shows the cyclic voltammograms of the GC rod only and of titanium-niobium oxide supported on the GC rod $\left(\mathrm{Ti}_{x} \mathrm{Nb}_{y} \mathrm{O}_{z} / \mathrm{GC}\right)$ heat-treated at $800{ }^{\circ} \mathrm{C}$ under reductive atmosphere. Because the amount of oxide catalyst loaded on the rod was small ( $c a .1 \mathrm{mg}$ ), the charge/discharge current was mainly derived from that due to the GC substrate. The electrical charge due to the oxide was estimated from the difference between the $\mathrm{CV}$ of $\mathrm{Ti}_{x} \mathrm{Nb}_{y} \mathrm{O}_{z} / \mathrm{GC}$ and that of $\mathrm{GC}$ only. Figure $\mathrm{S} 4$ shows the dependence of the electrical charge of the double layer of the oxides on the catalyst loading. The SEM images showed that the surface area of the catalysts decreased above $800{ }^{\circ} \mathrm{C}$ due to aggregation of the particles. However, a linear relationship was obtained, suggesting that the electrical charge was determined not by the heat treatment temperature but by the catalyst loading. Therefore, the trend in the apparent specific activity (ORR current density based on electrical charge) is similar to that of the mass activity. It is anomalous that the electrical charge is independent of the heat treatment temperature. The surface area estimated using the electrical charge may be different from that predicted from the SEM images. Because the electrical conductivity of even the catalysts prepared under reductive atmosphere is low, the surface area of the electrochemical active region in contact with the GC rod might be small. Thus, a more accurate estimation of the actual surface area of the catalysts is necessary. 


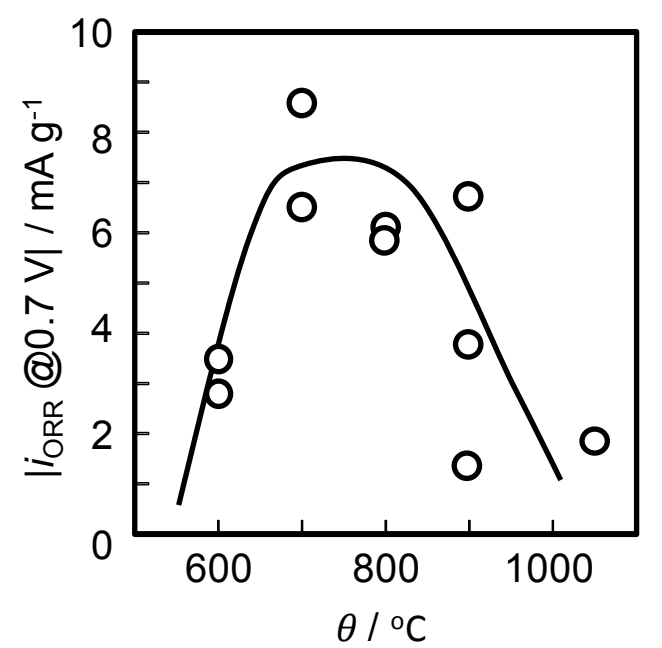

Figure 9. Dependence of $i_{\mathrm{ORR}} @ 0.7 \mathrm{~V}$ on temperature used for heat-treatment of the samples under reductive atmosphere.

\subsection{Relationship between ORR Activity and Physico-Chemical Properties}

The ORR activity was enhanced by reductive heat treatment in the region of 700 to $900{ }^{\circ} \mathrm{C}$. The XRD patterns indicated that the crystalline structure of the catalysts prepared under reductive atmosphere changed from anatase to rutile $\mathrm{TiO}_{2}$ around $800{ }^{\circ} \mathrm{C}$. On the other hand, the XPS spectra revealed that low valence state $\mathrm{Ti}$ is generated by heat treatment above $700{ }^{\circ} \mathrm{C}$ under reductive atmosphere. Therefore, reduction of the sample surface occurs around $700{ }^{\circ} \mathrm{C}$. The ionization potential is more sensitive to the surface state as shown in Figure $7 \mathrm{~b}$. Henrich et al. found that the work function (i.e., ionization potential in this study) of $\mathrm{TiO}_{2}$ decreased as the density of oxygen vacancies increased [18]. Therefore, the low ionization potential suggested that the catalysts heat-treated under reductive atmosphere at higher temperature had more surface defects. In this study, the oxygen vacancies as well as the valence changes induced by substitutional metal ions were found to produce localized electronic energy levels in the bandgap.

Figure 10 shows the relationship between the ionization potential and the ioRR @ $0.7 \mathrm{~V}$ of the catalysts prepared under reductive atmosphere. A "volcano plot" with a maximum at $5.4 \mathrm{eV}$ was obtained, suggesting that the electronic state of the sample surface is suitable for the ORR.

Adsorption of oxygen molecules on the surface is required as the first step for the ORR to proceed. Many studies have demonstrated that surface defect sites are required for adsorption of oxygen molecules on the surface of the oxides [19]. Therefore, a larger number of surface defects furnishes more sites for adsorption of oxygen molecules. In addition, the interaction of oxygen with the catalyst surface is essential because adsorption of oxygen and desorption of water from the surface are both necessary for robust progress of the ORR. When the interaction of oxygen with the catalyst surface is strong, desorption of water does not proceed readily. On the other hand, when the interaction of oxygen with the catalyst surface is weak, less adsorption of oxygen molecules occurs. Therefore, there is an optimal strength for the interaction between oxygen and the catalyst surface. Metallic Ti adsorbs oxygen strongly because of the large adsorption energy of oxygen $\left(759 \mathrm{~kJ} \cdot \mathrm{mol}^{-1}\right)$ and the strong energy of the Ti-oxygen bonds (calculated: $625 \mathrm{~kJ} \cdot \mathrm{mol}^{-1}$ ) [20]. In the case of $\mathrm{Pt}$, the energy for adsorption of oxygen and the calculated Pt-oxygen bond energy are $272 \mathrm{~kJ} \cdot \mathrm{mol}^{-1}$ and $385 \mathrm{~kJ} \cdot \mathrm{mol}^{-1}$, respectively [20]. Therefore, 
the corresponding values for Ti are much larger than those of Pt. As the degree of oxidization of metallic $\mathrm{Ti}$ increases, the interaction of oxygen with $\mathrm{Ti}$ on the catalyst surface is weakened because the oxide ions attract the electrons in the highest occupied molecular orbital of Ti thereby conferring a positive charge on Ti, i.e., higher valence state. Because the ionization potential is related to the strength of the interaction between the surface of the specimen and oxygen, the volcano plot shown in Figure 10 suggests that there is a suitable interaction between the surface of the specimen and oxygen. Consequently, the strength of the interaction between oxygen and the oxide surface could be manipulated by controlling the local energy level of the electrons, i.e., by controlling the valence changes induced by the substitutional ions and/or oxygen vacancies.

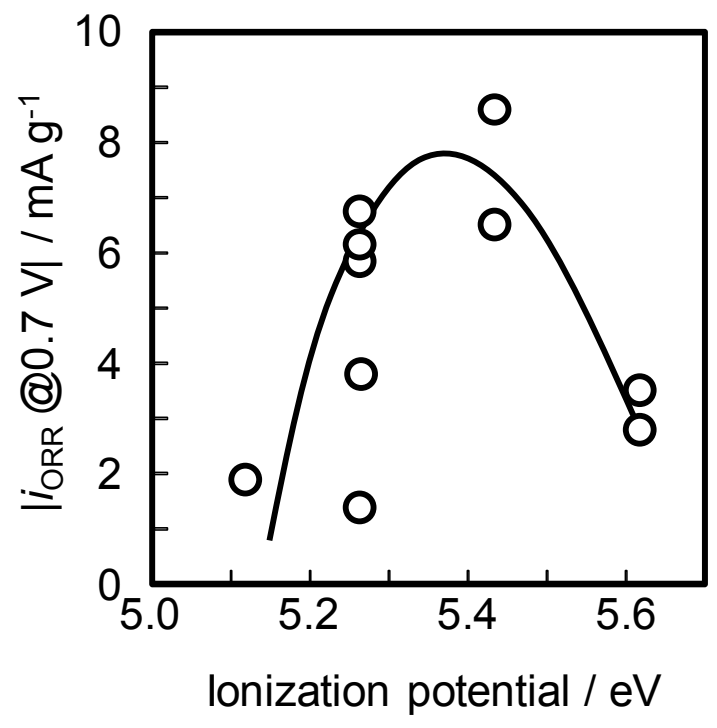

Figure 10. Relationship between the ionization potential and the ioRR@0.7 V of the catalysts prepared under reductive atmosphere.

\section{Experimental Section}

The high concentration sol-gel method [21,22] was used for preparation of the precursor. A $30 \mathrm{~cm}^{3}$ aliquot of titanium(IV) tetraisopropoxide $\left(\mathrm{C}_{12} \mathrm{H}_{28} \mathrm{O}_{4} \mathrm{Ti}\right.$, 99.99\%, Sigma-Aldrich Japan Co. LLC, Tokyo, Japan) and $4 \mathrm{~cm}^{3}$ of niobium(V) ethoxide $\left(\mathrm{C}_{10} \mathrm{H}_{25} \mathrm{NbO}_{5}, 99.95 \%\right.$, Aldrich) were dissolved in $200 \mathrm{~cm}^{3}$ of 2-methoxyethanol with a $\mathrm{TiO}_{2}: \mathrm{Nb}_{2} \mathrm{O}_{5}$ weight ratio of $8: 2$. The mixed solution was maintained at $-50{ }^{\circ} \mathrm{C}$, and $15 \mathrm{~cm}^{3}$ of 2-methoxyethanol in $15 \mathrm{~cm}^{3}$ of pure water was added to the mixed solution dropwise. The temperature of the solution was raised to $80{ }^{\circ} \mathrm{C}$ and maintained for 3 weeks as an aging treatment, resulting in the formation of nano-sized complex oxides. The precipitates were dispersed in 2-methoxyethanol to obtain a dispersion of nano-sized titanium-niobium oxide.

A $3-\mathrm{mm}^{3}$ aliquot of the dispersion was dropped onto a GC $\operatorname{rod}(\varphi=5.0 \mathrm{~mm}$; TOKAI CARBON CO., LTD., Tokyo, Japan) followed by drying at room temperature. The coated rod was heat-treated at $600{ }^{\circ} \mathrm{C}$ for $10 \mathrm{~min}$ in air as a pre-heat-treatment step to remove organic species and carbon residue and to provide sufficient electrical contact between the titanium-niobium oxide and the GC substrate. Subsequently, samples of titanium-niobium oxide supported on the GC rods were heat-treated at $600,700,800,900$, and $1050{ }^{\circ} \mathrm{C}$ in air or in Ar containing $4 \% \mathrm{H}_{2}$ to prepare the working electrodes. For the powder XRD and ionization potential measurements, $3 \mathrm{~cm}^{3}$ of the dispersion of nano-sized 
titanium-niobium oxide was dried on a hot plate at $160{ }^{\circ} \mathrm{C}$ to obtain the powder samples. The powders were then heat-treated at $600{ }^{\circ} \mathrm{C}$ for $10 \mathrm{~min}$ in air to remove organic species and carbon residue. The powders were subsequently heat-treated at $600,700,800,900$, or $1050{ }^{\circ} \mathrm{C}$ in air or in Ar containing $4 \% \mathrm{H}_{2}$ for powder XRD and ionization potential measurements.

The morphologies, crystalline structures, and chemical states of the synthesized catalysts were investigated by transmission electron microscopy (TEM; JEOL Ltd., JEM-2100F, Akishima, Japan, $\mathrm{X}$-ray diffraction (XRD; Rigaku Corporation, Ultima IV, X-ray source: $\mathrm{Cu}-\mathrm{K} \alpha$, Akishima, Japan) and X-ray photoelectron spectroscopy (XPS; ULVAC-PHI, Inc. Quantum-2000, X-ray source: monochromated Al-Ka radiation, Chigasaki, Japan). The peak of the $\mathrm{C}-\mathrm{C}$ bond attributed to free carbon at $284.6 \mathrm{eV}$ in the $\mathrm{C} 1 \mathrm{~s}$ spectrum was used to compensate for surface charging.

The ionization potential of the specimens was measured using a photoelectron spectrometer surface analyzer (Model AC-2, RIKEN KEIKI Co., Ltd., Tokyo, Japan) [23,24].

All electrochemical measurements were performed in $0.1 \mathrm{~mol} \cdot \mathrm{dm}^{-3} \mathrm{H}_{2} \mathrm{SO}_{4}$ at $30{ }^{\circ} \mathrm{C}$ with a 3-electrode cell. A reversible hydrogen electrode (RHE) and a glassy carbon plate were used as the reference and counter electrodes, respectively. As a pre-treatment, $300 \mathrm{CV}$ cycles were performed in $\mathrm{O}_{2}$ atmosphere in the range of 0.05 to $1.2 \mathrm{~V}$ with respect to the $\mathrm{RHE}$ at a scan rate of $150 \mathrm{mV} \cdot \mathrm{s}^{-1}$. Slow scan voltammetry was performed under $\mathrm{O}_{2}$ and $\mathrm{N}_{2}$ atmosphere in the range of 0.2 to $1.2 \mathrm{~V}$ with respect to RHE at a scan rate of $5 \mathrm{mV} \cdot \mathrm{s}^{-1}$. The ORR current density, ioRR, based on the mass of the catalyst (mass activity), was determined by calculating the difference between the current density under $\mathrm{O}_{2}$ and $\mathrm{N}_{2}$ atmosphere.

\section{Conclusions}

In order to develop noble-metal- and carbon-free cathodes, titanium-niobium oxides were prepared for use as oxide-based cathodes and the factors affecting the ORR activity and active sites were evaluated. The high concentration sol-gel method was employed for preparation of the precursor. Secure adhesion between the oxide catalysts and the substrate was achieved by heating the precursor supported GC rod at $600{ }^{\circ} \mathrm{C}$ in air to maintain the electrical contact as a pretreatment step. To create ORR active sites, the precursor supported $\mathrm{GC}$ rod was heat-treated in the temperature range of 600 to $1050{ }^{\circ} \mathrm{C}$ in air or in Ar containing 4\% $\mathrm{H}_{2}$. Heat treatment in reductive atmosphere at $700-900{ }^{\circ} \mathrm{C}$ was effective for conferring ORR activity to the catalysts. Notably, the onset potential for the ORR was approximately $1.0 \mathrm{~V}$ vs. RHE for the catalyst prepared at $700{ }^{\circ} \mathrm{C}$. This high onset potential indicates the high quality of the active sites for the ORR. XRD, XPS and ionization potential measurements suggested that localized electronic energy levels were produced by heat treatment under reductive atmosphere. The electronic energy levels produced by the valence changes of Ti induced by substitutional metal ions and/or oxygen vacancies might govern adsorption of the oxygen molecules. Therefore, the strength of the interaction between oxygen and the oxide surface can be manipulated by controlling the valence changes induced by the substitutional ions and/or oxygen vacancies.

\section{Acknowledgments}

The authors acknowledge financial support from the New Energy and Industrial Technology Development Organization (NEDO). This work was conducted under the auspices of the Ministry of 
Education, Culture, Sports, Science and Technology (MEXT) Program for Promoting the Reform of National Universities.

\section{Author Contributions}

A.I. designed the research; Y.T. performed research; M. C. analyzed XPS data; Y.O. analyzed data; and all authors provided feedback during preparation of the manuscript.

\section{Conflicts of Interest}

The authors declare no conflict of interest.

\section{References}

1. Jasinski, R. A new fuel cell cathode catalyst. Nature 1964, 201, 1212-1213.

2. Jaouen, F.; Goellner, V.; Lefevre, M.; Herranz, J.; Proietti, E.; Dodelet, J.P. Oxygen reduction activities compared in rotating-disk electrode and proton exchange membrane fuel cells for highly active Fe-N-C catalysts. Electrochim. Acta 2013, 87, 619-628.

3. Wu, G.; More, K.L.; Johnston, C.M.; Zelenay, P. High-Performance Electrocatalysts for Oxygen Reduction Derived from Polyaniline, Iron, and Cobalt. Science 2011, 332, 443-447.

4. Proietti, E.; Jaouen, F.; Lefevre, M.; Larouche, N.; Tian, J.; Herranz, J.; Dodelet, J.P. Iron-based cathode catalyst with enhanced power density in polymer electrolyte membrane fuel cells. Nat. Commun. 2011, 2, 416.

5. Ishihara, A.; Lee, K.; Doi, S.; Mitsushima, S.; Kamiya, N.; Hara, M.; Domen, K.; Fukuda, K.; Ota, K. Tantalum Oxynitride for a Novel Cathode of PEFC. Electrochem. Solid-State Lett. 2005, 8, A201-A203.

6. Ishihara, A.; Tamura, M.; Ohgi, Y.; Matsumoto, M.; Matsuzawa, K.; Mitsushima, S.; Imai, H.; Ota, K. Emergence of Oxygen Reduction Activity in Partially Oxidized Tantalum Carbonitrides: Roles of Deposited Carbon for Oxygen-Reduction-Reaction-Site Creation and Surface Electron Conduction. J. Phys. Chem. C 2013, 117, 18837-18844.

7. Ishihara, A.; Chisaka, M.; Ohgi, Y.; Matsuzawa, K.; Mitsushima, S.; Ota, K. Synthesis of nano- $\mathrm{TaO}_{x}$ oxygen reduction reaction catalysts on multi-walled carbon nanotubes connected via a decomposition of oxy-tantalum phthalocyanine. Phys. Chem. Chem. Phys. 2015, 17, 7643-7647.

8. Okada, Y.; Ishihara, A.; Matsumoto, M.; Imai, H.; Kohno, Y.; Matsuzawa, K.; Mitsushima, S.; Ota, K. Electrochemical stability of zirconium oxide-based electrocatalysts made from oxy-zirconium phthalocyanines. J. Electrochem. Soc. 2015, 162, F959-F964.

9. Ishihara, A.; Hamazaki, M.; Kohno, Y.; Matsuzawa, K.; Mitsushima, S.; Ota, K. Titanium-niobium oxides mixed with $\mathrm{Ti}_{4} \mathrm{O}_{7}$ as noble-metal- and carbon-free cathodes for polymer electrolyte fuel cells. Electrochim. Acta, submitted.

10. Hamazaki, M.; Ishihara, A.; Kohno, Y.; Matsuzawa, K.; Mitsushima, S.; Ota, K. Evaluation of durability of titanium-niobium oxides mixed with $\mathrm{Ti}_{4} \mathrm{O}_{7}$ as non-noble and carbon-free cathodes for PEFC in $\mathrm{H}_{2} \mathrm{SO}_{4}$ at $80^{\circ} \mathrm{C}$. Electrochemistry, in press. 
11. Arashi, T.; Seo, J.; Takanabe, K.; Kubota, J.; Domen, K. Nb-doped $\mathrm{TiO}_{2}$ cathode catalysts for oxygen reduction of polymer electrolyte fuel cells. Catal. Today 2014, 233, 181-186.

12. The American Ceramic Society. In Phase Equilibria Diagrams Volume XII Oxides; McHale, A., Roth, R., Gen, S., Eds.; The American Ceramic Society, United States of America: Westerville, OH, USA, 1996; p. 119.

13. Sedneva, T.A.; Lokshin, E.P.; Belikov, M.L.; Belyaevskii, A.T. $\mathrm{TiO}_{2}$-and $\mathrm{Nb}_{2} \mathrm{O}_{5}$-Based Photocatalytic Composites. Inorg. Mater. 2013, 49, 382-389.

14. Haukka, S.; Lakomaa, E.-L.; Jylha, O.; Vilhunen, J.; Hornytzkyj, S. Dispersion and Distribution of Titanium Species Bound to Silica from TiCl4. Langmuir 1993, 9, 3497-3506.

15. González-Elipe, A.R.; Munuera, G.; Espinos, J.P.; Sanz, J.M. Compositional changes induced by $3.5 \mathrm{keV} \mathrm{Ar}{ }^{+}$ion bombardment in Ni-Ti oxide systems: A comparative study. Surf. Sci. 1989, 220, 368-380.

16. Bahr, M.K. ESCA studies of some niobium compounds. J. Phys. Chem. Solids 1975, 36, 485-491.

17. Olejniczak, M.; Ziolek, M. Comparative study of Zr, Nb, Mo containing SBA-15 grafted with amino-organosilanes. Microporous Mesoporous Mater. 2014, 196, 243-253.

18. Henrich, V.E.; Dresselhaus, G.; Zeiger, H.J. Observation of Two-Dimensional Phases Associated with Defect States on the Surface of $\mathrm{TiO}_{2}$. Phys. Rev. Lett. 1976, 36, 1335-1339.

19. Bourgeois, S.; Domenichini, B.; Jupille, J. Excess Electrons at Oxide Surfaces. In Defects at Oxide Surfaces; Jupille, J., Thornton, G., Eds.; Springer Series in Surface Sciences 58; Springer International Publishing: Basel, Switzerland, 2015; pp. 123-148.

20. Miyazaki, E.; Yasumori, I. Heats of chemisorption of gases. Surf. Sci. 1976, 55, 747-753.

21. Matsuda, H.; Mizushima, T.; Kuwabara, M. Low-Temperature Synthesis and Electrical Properties of Semiconducting $\mathrm{BaTiO}_{3}$ Ceramics by the Sol-Gel Method with High Concentration Alkoxide Solutions. J. Ceram. Soc. Jpn. 1999, 107, 290-292.

22. Matsuda, H.; Kobayashi, N.; Kobayashi, T.; Miyazawa, K.; Kuwabara, M. Room-temperature synthesis of crystalline barium titanate thin films by high-concentration sol-gel method. J. Non-Cryst. Solids 2000, 271, 162-166.

23. Kirihata, H.; Uda, M. Externally quenched air counter for low-energy electron emission measurements. Rev. Sci. Instrum. 1981, 52, 68-70.

24. Uda, M.; Nakagawa, Y.; Yamamoto, T.; Kawasaki, M.; Nakamura, A.; Saito, T.; Hirose, K. Successive change in work function of Al exposed to air. J. Electron. Spectrosc. Relat. Phenom. 1998, 88-91, 767-771.

(C) 2015 by the authors; licensee MDPI, Basel, Switzerland. This article is an open access article distributed under the terms and conditions of the Creative Commons Attribution license (http://creativecommons.org/licenses/by/4.0/). 